\title{
C.ONF-760645--3
}

\section{LA-UR -;6-1293}

TITLF: TRANSIJNT PHENOMENA IN THE SOLAR ATMOSPHERE AND SOLAR WIND

\author{
AUTHOR(S): J. T. rss!ing
}

SUBMITTED TO: International Syupos 1un on Solar Terrestrial Phya1c8, Boulder, Colorado, June 7-18, 1976.

\begin{abstract}
By acceplance of this apticle for publication. the publisher recognizes the Government's (license) rights in uny copyright und the Government and lts aut horized representalives have unrestricted right to reproduce in whole or in part sald article under any copyright secured by the publisher.
\end{abstract}

The I.on Alumos Sclentife L,aboratory requests that the publisher Identify this article as work performed under the auspicen of the USERDA. \section{solontific Inboratory of the University of Callfarnia los ALAMOS. NEW MEXICO 87544}

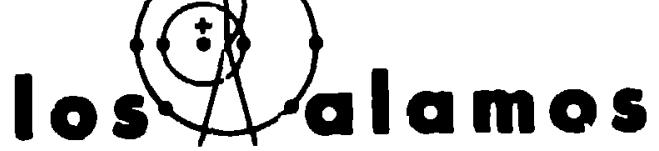
ALAMOS. NE

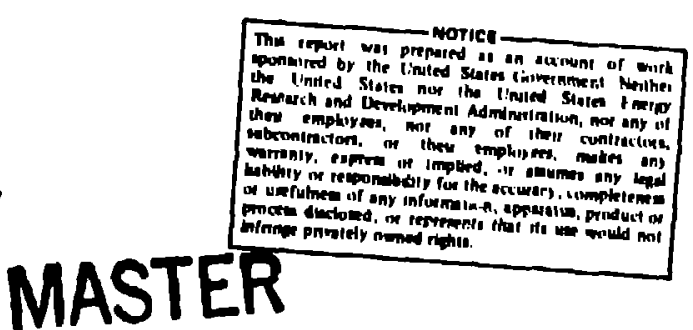

$\therefore$ - !.. . . : ....vi la Uividmited UNRE: ST'ATHS 
TRANSIENT PHENOMENA IN THE SOLAR ATMOSPHERE AND SOLAR WIND

\author{
J. T. Gosling \\ University of California, Los Alamos Sclentific Laboratcry \\ Los Alamos, New Mexico 87545
}

\begin{abstract}
Observations of transient disturbances in the solar atmosphere are reviewed with emphasis on coronal mass ejection events. Although mass ejection events are surprisingly comon (at least 66 were observed during the 227 day operation of the coronagraph on Skylab) and escape from the vicinity of the sinn at apeeds ranging from less than 100 to greater than $1200 \mathrm{~km} \mathrm{~s} \mathrm{~s}^{-1}$, present evidence strongly suggests that only the very fastest events produce shock wave disturbances in the solar wind at 1 AU. These fast events are almost always associated with large solar flares and metric favelength Type II and/or IV radio bursts. However, the majority of coronal mass ejection events are associated with eruptive prominences (or disappearing filaments) and escape from the vicintiy of the sun at speeds less than $500 \mathrm{~km} \mathrm{~s}^{-1}$. Although these latter events eject of the order of a few times $10^{15}$ grams of coronal material and $10^{31}$ ergs into Interplanetary space, they do not appear to affect significantiy the velocfty structure of the solar wind at $1 \mathrm{AU}$. However, they may be the suurce of anomalous, non-compressive density enhancements in the solar wind frequently observed at low and declining bulk flow speec's.

Statistical studies Indicate that most shock wave disturbances in the solar wind at 1 AU are caused by very fast mass efectlous assoclated with larze solar flares. On the other hand, at large hellocentric dictances (say beyond $3 \mathrm{AU}$ ) most Int:erplanetary shocks arise from the steepening of the commoniy observed high speed solar wind si:reams and thus. In general, have little to do with sulire actjivity.
\end{abstract}

\title{
Introduction
}

Controversies form an Important part of our sclentific heritage. Tws diatingulshed actent1strs $-T$. Gold and E. N. Parker - were the major protagonfots Iil a controversey in the late 1950's and early $1960^{\prime} \mathrm{s}$ concerning the origin of distirkbances in the solar wind and the magnetic field geometr; assoclated with these disturbances. Respective positions of the protagonists were staked out in scleutific articles (e.g. Gold, 1959; Parker, 1961) and debates on the subject added aplce to at least a few sclentific gatherings (e.g. Davis, 1966; Parker, 1959). The crux of the argument between Gold and 
Parker boiled down to the question: At what height and where in the solar atmosphere do major solar wind disturbances originate? it was Parker's opinion that major solar wind disturbances probably resulced from a sudden increase in the rate of expansion of a part of the solir corona already previously expanding, i.e. a region already magnetically open to interplanetary space. According to this viewpoint, no additional magnetic flux is carried outward by disturbances, and all field lines in the solar wind remain open to the boundary of the heliosphere. Gold, on the othe: hand, was of the opinion that solar wind disturbances began with the ejection of material from regions low in the solar atmosphere where closed magnetic fields ordinarily restrained the gas from expanding. Both scientists agreed that if Gold's suggestion was correct closed magnetic loops or tongues would propagate out tliraugh the solar wind.

The Gold-Parker debate is of more than mere historical interest, for the problem of the field line geometry of solar wind disturbances remains unsolved (e.g. Gosling and Roelof, 1974; Gosling, 1975). Further, although we now know that Gold was essentially cnrrect in suggesting that most major solar wind disturbances begin with the ejection of material from regions not previously participating directly in the coronal expansion, we have an excess of such ejections to explain. That is, there seen to be many more mass ejections from low in the solar atmosphere chan major solar wind disturbances in the solar. wind near $1 \mathrm{AU}$. Our discussion here will concentrate on reviewing those properties of solar mass ejection events that appear to be most germane to understanding their subsequent propagation through interplanetary space. At the end of this discussion we will suggest an identification of mass ejection events in the solar wind at $1 \mathrm{AU}$.

Eruptive phenomena on the surface of the sun and in the lover solar atmosphere (e.g. eruptive prominences, disappearing filaments, flare sprays) have been familiar to astronomers since the advent of :la observations of the sun. (See e.g. reviews in öhman, 1968, and Tandberg-Hanssen, 1967.) However, with only $\mathrm{H}$ o observations avallable it is not possible to determine the coronal response to or participation in these eruptions. Further, one can usually not decermine if the eruptive material actually escapes from the gravitational pull of the sun. Radio burst studies (see e.g. reviews by Fild and Smerd, 1972; Smerd and Dulk, 1971; Stone, 1974) and green line and white light studies of the corona with ground-based coronagraphs (e.g. PeMastus et al., 1973; Hansen et al., 1974) confirm that the corona often actively participates in eruptive behavior. Nevertheless, it was only with the successful oxbiting of satellite coronagraphs (e.g. Koomen et a1., 1974; MacQueen et al., 1974) that the dymanical nature of eruptive events in the corona cuuld be properly apprectated and quantitatively documented.

\section{The Appearance of Cororial Mass Ejection Events}

An example of a mass efection event in the corona, photographed in white light by the corcnagraph experiment on Skylab, is shown in Figure 1. At least 66 qualitatively similar events were observed by the coronagraph experiment durtig its 227 days of operation (May 1973 - January 1974). In particular, the loop-like appearance, so reminiscent of Gold's magnetic bottles, is a cormon characteristic of most of these events (Gosling et al., 1974; Hildner et al., 1975a; 1975b). The "clouds" of gas described by the 


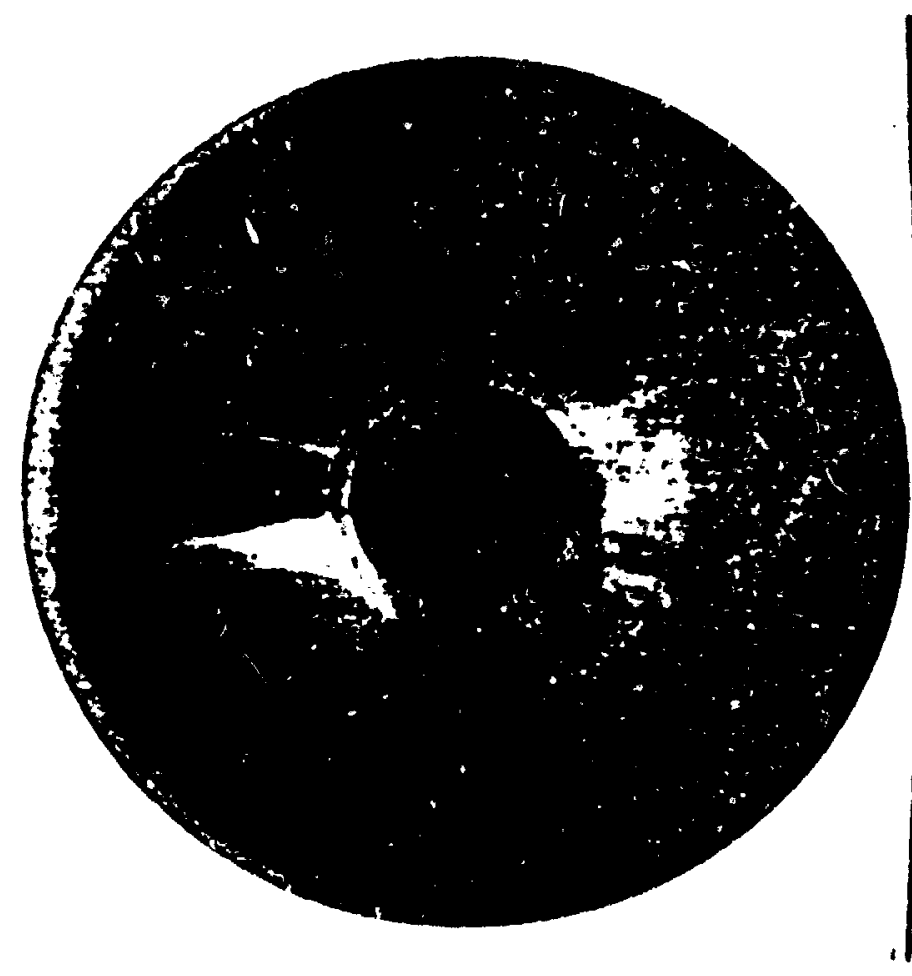

Figure 1. A coronal mass ejection cvent photographed ot 1448 UT o.s 10 August 1973 by the High Alt1tude Observatory's white 1ight coronagraph experiment on Skylab. Tine field of view is 6 solar diameters. The sun is osscured by the occulting disk at the center whose effective diametcr is 1.5 solar dianetcrs. The very itrong radial sradient of coronal radiarice has been actenuated by visnerting within the instrument and by dodging the print. From cosling et e1. (1974).

OSO 7 coronagruph exper Imenters (e.g. Brueckner, 1972; Kooomen et al., 1974) are aloost certainly fust the brighter portions of these loop-like structures, a result of the OSO 7 coronagraph's low sensitivity and resolution. Time lapse photographs reveal that the loops of material nove outward while apparently retaining their connection to the sun along the footpolnts of the 10ops. All loop-like structures observed within the Skylab coronagraph fleld of view (approximately 2-6 solar radif $\left(R_{0}\right)$ from sun center in the plane of: the sky) escaped outward, most of them moving at constant or ever increasing speed. RTE bow waves form around the material efecta which compress the amblent corona ahead of the ejecta and deflect the ambient corona frod its outward path; the bent appearance of the coroual ray just to the south of the outermost loop In Figure 1 is caused by the ray's interaction with such a bow wave.

\section{Associations of Maes Ejecition Events With Other Forms of Solar Activity}

Approximately half of the mass ejection events observed wth the Skylab coronagraph can be directly assoclated with other forms of solar activity Goslinz et al., 1974; Munro et al., 1976). For example, the 10 August 1973 event shown In Figure 1 was accompanted by an eruptive prowinence on the west limb of the sun. Thls $38 s 0 r i a t i o n$ is a common one; of che events with lonown assoclattons with surface activity, approximately $2 / 3$ accompanied eruptive prominences. The other $1 / 3$ were assoclated with large solur flares (1 B or greater); these flares all produced sprays observabie in Ha. It is probable that most of the events with no known associations with surface activity were assoclated with solar activity on the back alde of the sun. Further evidence of the strong correlation between surface solar activity and coronal disturbances as observed with the Skylab coronagiaph can be found in 


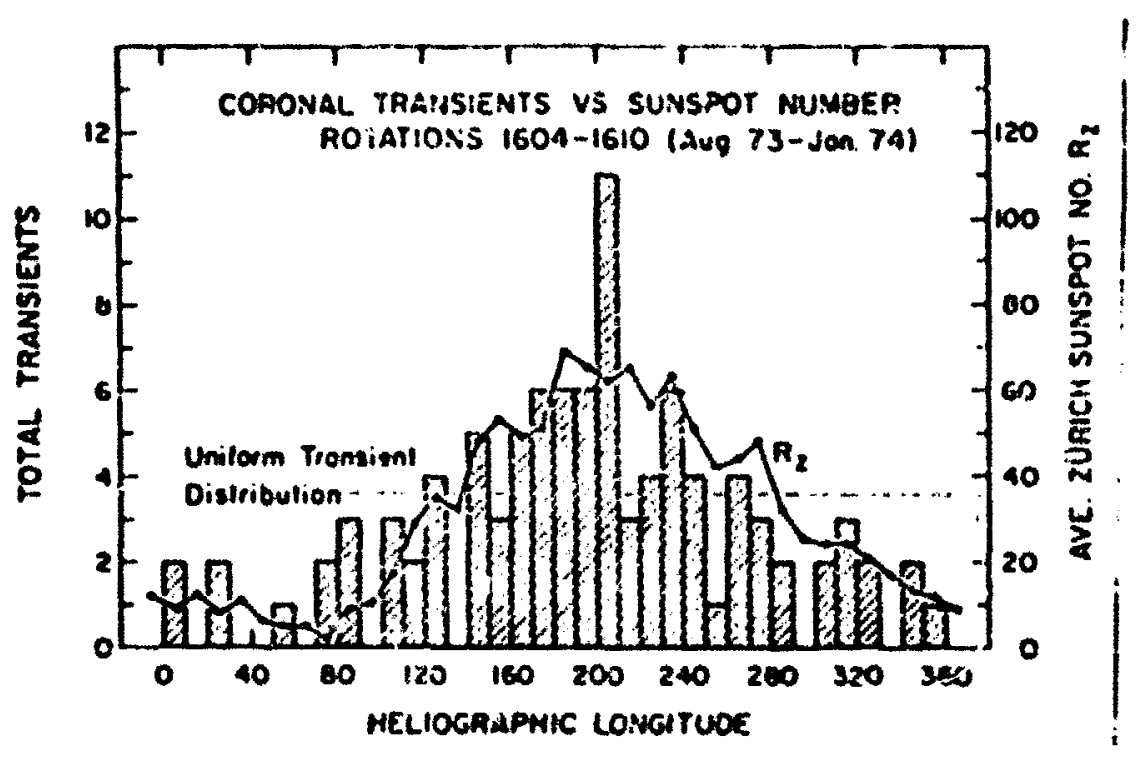

Figure 2. Total number of coronal cransients observel durlng seven solar rotaitons and average sunspot nuaber vs longltude. From llildner at al. (1976).

Figure 2 where the total nuaber of observed coronal events durfing suven solar rotations and the nuernge sunspot nusber are plotted vs solar longItude (Hildner et al., 1976). Note how both the coronal dlrturbarce and sunspot nuebers peak nenx hellographic longlicude 200 degrces.

Desplte the close asscciation of coronal mass ejections with flare sprays and cruptive prominences, te ls not true that the coronal events arc coaprised primarily of chromospheric material throm up into the corona. On the contrary, situltaneous obsetvations of prosinence material in its and HeII SO4A and of coronal disturbances with the skylab coronagraph reveal (H11dner et 1.. 1975b; Poland anc Yynro, 1976): 1) nost of the aatertal in the coronal event originates in the lower corona; the chrosospheric eaterial corsprises only a small fraction of the cotal; and 2) the entre event is far larger, more energet1c, and longer lasting than would be inferred fron the Ha ubservations elone. This is lllustrated for the event of 26,27 August 1973 by the drawing to scale in Figure 3 . Note how the leading edge of the coronal event extends out to alcost $3 \mathrm{R}$, while the prosinence loups are conitralned to a height less than $1.8 R_{0}$.

Metxic wavelength type II ard IV radjo bursts often occospany coronal stass ef ection events (Cosling et al., 1974; Stewart et al., 1974a,b). Ground detected burats of this sort which originate within about \pm 45 degrees of the solar limb alrose lnvarlably are associnted wth coronagraph-detected rass ejections. On the other hand, many mass ejection events do not produce observable metrlc wavelength type II anc IV bursts. We shall sce in the following section that the spead with which the materlal moves outinard appears to determine whethar or not a given disturbance will gencrate a netric vavelength burst. 


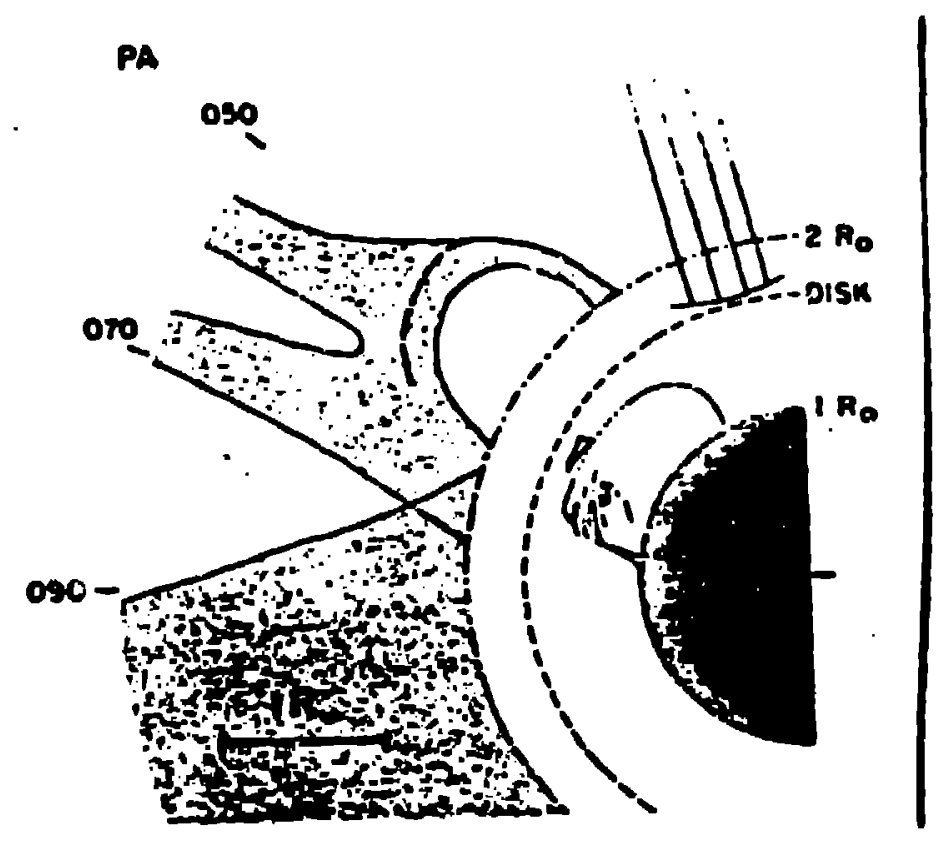

Pigure 3. A drawing of the appearance of the solar atmosphere above the northesst liob of the sun at 0000 UT on 27 August 1973. The Inner loop to a large, lowly rlaing prominence observed in both Ha and He II $34 A_{\text {. The }}$ wuch larger outer loop Is a coronal mas ejection event observef with the Skylab coronagraph experiment. The large spatial separation between the propinence and the coronal event shows that the corunal mass efecta does not or Iginate in the prominence and that the coronal event is far larger than vould be Inferted from prominence observations alone. From Ilildner et al. (1975b).

\section{The Speeds of Coroncl Hase Ejectlon Events}

The outward epeede of mase efection cvents observed by the OSO 7 and skylab coronagraph experiaents varied over a range extending from leas than 100 to greater than $1200 \mathrm{ks} \mathrm{s}^{-1}$. A hietog:am of the speede of the leading adgen of the events observed by the Skylab coronegraph is displayed in the upper panal of Figure 4 (Cosilng et al. 19?6a). For all cvente the average opeed wthin the flald of view of the exporimant (approximately 2 to $6 R_{0}$ ) uac $470 \mathrm{~km} \mathrm{~g}^{-1}$, and approximately equal numbers of cvente were found above and below this average. It 1s Interesting that this average apegd 18 close to tha everage oolar wind epead at 1 AU (approximetely 450 kn $a^{-1}$ ), although the range of obeerved colar wind apeeda (e.8. Gosilng et al., 1976b) 1. conalderably lase than that of coronal mese jection eventa.

The muber distribution of speeds for corcsis evente asociated with eruptive proplinances and with flares are displayed in the cecond and third panele of Flgure 4. The distributions are distinctly different. The typical llare asuoclated event had a opeed wore than twice as great as the typleal prominence associfted event, the average speed for each type of eve: te being 775 and $330 \mathrm{~km} a^{-1}$ reapectively. Note that the average opead for the flare asoclated ovente 1 considerably greater than the average flow opeed of the colar wind at $1 \mathrm{AU}$, while that of the prominence asociated events is alightly leas than this average. 


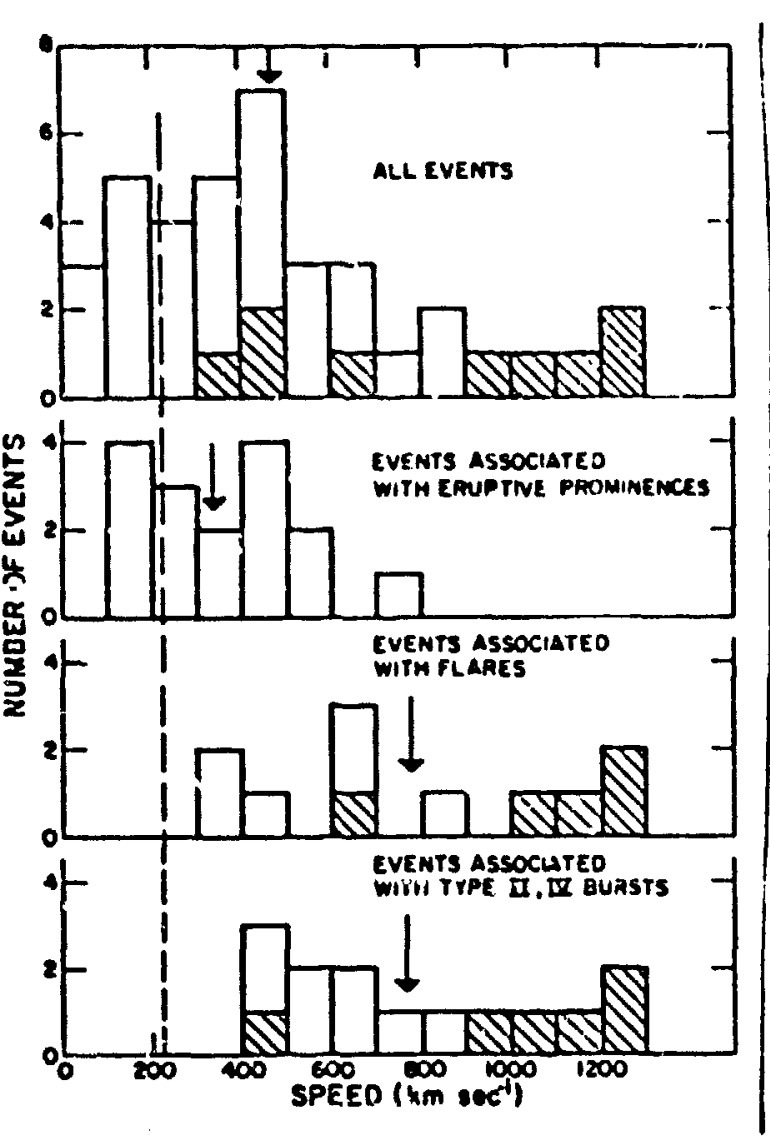

Figure 4. The number distribution of measured speeds of the leading edges of mass ejection events (upper panel) and the number distributions of speeds for mass ejection events associated with eruptive prominences, flares, and type II and IV radio bursts (lower panels). The cross hatihed pattern is used when the speed is only a lower limit esticate. The arrows indicate average values; the vertical dashed line indicates the gravitational escape speed for material 6 solar rad?: from sun center. From Gosling et a1. (1976a).

From exanination of the lower panel in Figure \& it is apparent that metr1c wavelength type II and IV radio bursts are assostated only with events moving faster than about $400 \mathrm{~km} \mathrm{~s} \mathrm{~s}^{-1}$; all but two events moving faster than $500 \mathrm{~km} \mathrm{~s} \mathrm{~s}^{-1}$ produced either a type II or IV radio burst or both. Because of thelr high speed, most of the flare associated events produced bursts of this sort; several of the faster prominence events did so as well. According to Wild and Smerd (1972) and others, metric waveiength type II bursts are generated by shocks traveiling outward through the corona; slaflarly Dulk et al. (1976) suggest that some type IV bursts are also produced by shocks in the corona. This suggests that the bow waves running in front of coronal mass efection events become shocks when their speed exceeds 400 or $500 \mathrm{~km} \mathrm{~s}^{-1}$. If 80, then the characteristic speed with which NWD signals propagate in the lower ( 1.1 to $3 R_{0}$ ) corona, where metric wavelength bursts are generated, must be sbout 400 ro $500 \mathrm{~km} \mathrm{~s} \mathrm{~s}^{-1}$.

\section{The Mass and Energy Ccntent of Mass Ejection E sents}

Satellite coronagraphs observing in white light (such as the oso 7 and Skylab instruments) can not measure disturbances with a mass content below a few times $10^{14}$,xams. This threshold sensitivity depends somewhat upon the geonstry of an event and arises because of tise sirface brightiness of the background dust and electron coronas. In s.ddition, thus far no comprehensive analysis of the mass and energy content of coronal disturbances detected by the OSO 7 and Skylab coronagraphs has been performed. llowever, sstimates 
Table 1

\begin{tabular}{|c|c|c|c|c|}
\hline $\begin{array}{c}\text { Event Date } \\
1973 \\
\end{array}$ & $\begin{array}{c}\text { Mass } \\
\text { (grams) } \\
\end{array}$ & $\begin{array}{l}\text { Energy } \\
\text { (ergs) }\end{array}$ & $\begin{array}{c}\text { Associated } \\
\text { Surface } \\
\text { Event } \\
\end{array}$ & Reference \\
\hline $\begin{array}{l}11 \text { Jan. a } \\
11 \text { Jan. b } \\
10 \text { June } \\
10 \text { Aug. } \\
21 \text { Aug. } \\
26,27 \text { Aug. } \\
7 \text { Sept. } \\
14,15 \text { Sept. }\end{array}$ & $\begin{array}{l}17 \times 10^{15} \\
8 \\
5.4 \\
4 \\
8 \\
1 \\
24 \\
2.7\end{array}$ & $\begin{array}{l}10 \times 10^{30} \\
? \\
8.7 \\
8.4 \\
10 \\
2 \\
110 \\
5.4\end{array}$ & $\begin{array}{l}\text { Flare } \\
\text { Flare } \\
\text { EPL } \\
\text { EPL } \\
\text { EPL } \\
\text { EPL } \\
\text { Flare } \\
\quad ?\end{array}$ & $\begin{array}{l}\text { Stewart et al. (1974a) } \\
\text { Stewart et al. (1974b) } \\
\text { Hildner et al. (1975a) } \\
\text { Gosling et al. (1074) } \\
\text { Poland anc Ninro (1976) } \\
\text { H1ldner et al. (1975t) } \\
\text { Gosling et a . (1975) } \\
\text { Dulk et al. (1976) }\end{array}$ \\
\hline
\end{tabular}

Mass and energy estimates of some large mass ejection eventw.

for some of the brighter ( $1 . e$. more massive) events are avallable $n$ the 11terature and are sumarized in Table 1. For these iarge events the mass estimates range from $10^{15} \sim 2.4 \times 10^{16}$ grans, and the energy estimates range from $2 \times 10^{30^{\circ}}-1.1 \times 10^{32}$ exgs. Although sizable, these estimates in general fall considerably below estimates of the wass and energy content of shock wave disturbances in the solar wind at $1 \mathrm{AU}$.

\section{Frequency of Occurrence of Mass Ejection Events}

We have previously alluded to the fact that at least 66 mass ejection events were detected by the Skylab coronagraph during 1ts 227 days of operation. Because the cornnagraph observes events projected against the plane of the sky (i.e. perpendicular to the sun-earth Iine), it is most sensitive to events which occur near the solar limbs. If we assume that events observed by the colonagraph originated within \pm 45 degrees of the solar Iimb and that no particular direction in space was preferred during the Skylab interval, then approximately 33 ejections should have occurred within \pm 45 degrees of the solar central meridian. Considering the spatial extent of mass efection events (see Figure 1) it appears reasonable to assume that the large mafority of these 33 events would have reached the vicinity of the earth.

\section{A Direct Correlation of a Mass Ejection Event with a Shock Wave Disturbance in the Solar Wind at 1 AU}

Direct correlations between coronagraph ohserved inass ejections and disturbances in the solar wind near 1 AU are difficult because the coronagraph observations ara strongly blased towazd the solar 1imbs while nost solar wind observations ace made near the eartîn. Thus far tt has only been posstble to asßoclate directly a solar wind disturbance at 1 AU with an observed coronal mass ejection event on one occasion (Gosing et al., 1975). Following a 2B flare at W46S18 on 7 Septeraber 1073 a masaive $\left(2.4 \times 10^{16}\right.$ $\left.\mathrm{gm}^{\mathrm{m}}\right)$ and rapldiy moving $\left(\sim 960 \mathrm{~km} \mathrm{~s}^{-1}\right)$ ejection was observed with the Skylab 
coronagraph. Metric wavelength type II and IV radlo bursts accompanled the :utburst of material. Approximately two days later a very large shosk wave disturbance (Figure 5) was observed at Pioneer 9 . As can be seen ill the figure, during the 7-9 September perlod Pioneer 9 was located at a solar longltude of 41 degrees west, almost directly above the flare site. Estimates of the mass and energy content of the solar wind disturbance nre in reasonably good agreement with the corcnal estiuntes, and the shocle speed at $1 \mathrm{AU}$ and transic time from the sun to 1 AU fit nicely the estimates of a numerical model of disturbance propagation in the solar wind (Hundhausen and Gentry, 1969). Thus, we can be confident in this case that the coronal mass efection event was the source of the shock vare disturbance observed at 1 AU.

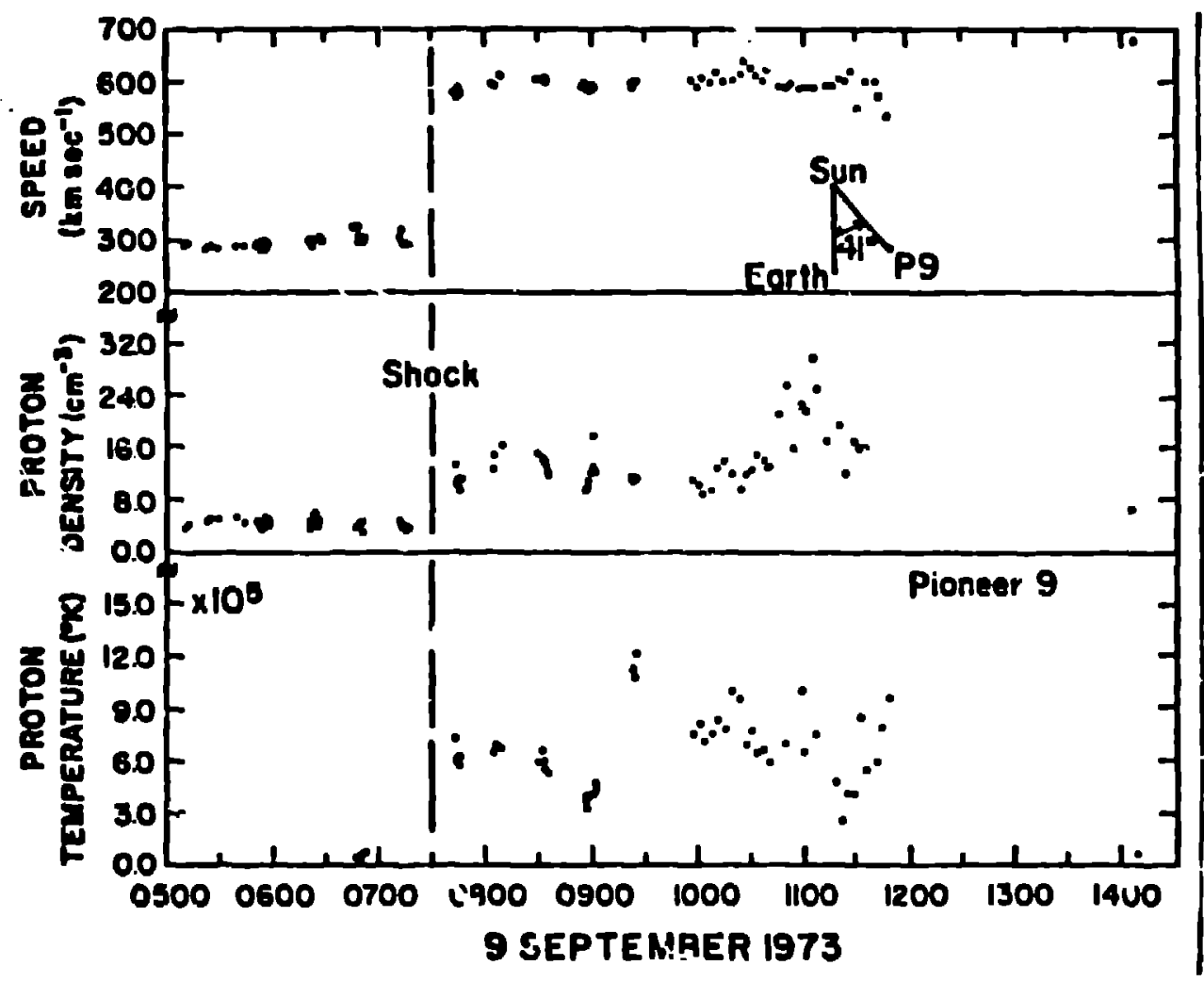

Figure 5. A large solar ulnd shock wave digturbance observed by Ploneer. 9 oi 9 September 1973. A very large solar flare, type II and IV radio bursts, and coronal mass ejection event occurred approximately 2 days earlier at W46 518, almost directly at the subsolar point for Pinneer 9. From Gosilng et al. (1975). 
A Search for a Ceneral Association Betwaen Coronal Mass Ejection Events and Soiar Hind Disturbances

Let us now brlefly sumarize several characteristics of mass ejection events discussed to this point.

1) Mass ejection events are generally associated with surface manifestations of solar activity, but more of ten with eruptive prominences than with solar flares (approximately in the ratio $2: 1$ ).

2) Mass ejection everts exhibit a wide rangs of outward speeds, On the average, flare assoclated events travel outward considerably faster than do prominence assoclated events (775 vs $330 \mathrm{~km} \mathrm{~s} \mathrm{~s}^{-1}$ ).

3) Nost events moving outward at speeds greater than about $500 \mathrm{~km} \mathrm{~s}^{-1}$ produce ground-detected wetric wavelength type II or IV bursts, or both. Events with speeds less than about $400 \mathrm{~km} \mathrm{~s}$ apparently never produce radio bursts of this sort.

4) A typical mass ejection event contains of the order of a few times $10^{15} \mathrm{~g}-2 \pi \mathrm{s}$ and has an energy associated with it of approximately $10^{31}$ ergs.

5) During the 8-month Skylab interval approximately 30 mass ejecta should have been directed earthward.

6) One example has been documented wherein a large and rapidly moving mass efection in association with a 2B flare produced metric wavelength type II and IV radio bursts and a major shock wave disturbance in the solar wind at $1 \mathrm{AU}$.

The question we woult now like to address is the following: What is the overall effert of thes $\approx$ mass efections upon the solar wind as observed neai 1 AU? The example of 7-9 September 1973 and previous statistical studies (e.8. llundhausen, 1972a; Chao and Lepping, 1974) indicate that the faster ruving ejections, which are usually assuciated with large solar flares and which usually produce metric wavelength type II and/or IV radio bursts, also usually produce shock wave disturbances in the solar wind at 1 AU. The reason they do produce such disturbances is that their outward speeds usually greatly exceed the speed of the solar wind gas into which they propagaze. The flare assoclated events cust also be the most massive and energetic of the coronal events, for measurements near the earth indicate that the average shock wave disturbance in the solar wind contains $3.5 \times 10^{16}$ grams and $1.4 \times 20^{32}$ ergs (Hundhausen, 1972b). (Of course the 1 AU estimates could be in error for they depend upon an assumption of the cross-sectional area of solar wind disturbances. The area used in deriving the solar wind escimates correspond 3 to $1 / 4$ of the 1 AU sphere centered on the sun; it is quite possible that most shock wave disturbances a.e not this broad.) These average solar wind values are near the upper limit of presently measured coronal values.

On the other hand, it appears unilkely that the slower moving mass efection events, which are usually assoclated with eruptive prominences, produce shock wava disturbances in the solar wind at i Ali. For one thing, their speeds close to the sun do not appear to be high enough to perturb strongly the fiow of the wind at larger distances. Also, they contain less mass and energy than normally assoclated with shock wave disturbances at 1 AU. And, finally, they occur much more frequently than do stoci wave disturbances. During the Skylab interval not a single shock wave disturbance was detected by the earch-orbitinb $1 \mathrm{mp} 7$ and 8 satellites. There are, of course, gaps in the Imp 7 and 8 solar wind data caused by the passage of the 
satellites behind the earth's bow shock; a total of 5 geomagnetic stiden ronmencements (SC's) occurred in these dato gaps. If wa assume that all of these SC's were produced by shocks, then 5 seems to be the upper linit for the number of shocks trat impacted upon the earth's manetosphere during this interval (May 1973 - January 1974). Yet, we estinated earlicr that approximately 30 mass ejections were directed cartiward.

It is also unlikely that the slow moving, crupive prominence associated events produce high speed solar wind streans; vircually all of thc iigh speed streams which occurred during the Skylao intervar are thougint to have orjginated in coronal holes (Sheeley et a1., 1976; Ifundhausen et a1., 1976). What, then, happens to these relatively comion, but slow-moving, coronal mass ejecta? In the next section we suggest that these slow moving coronal events may be the source of anomalous density enhancezents in the solar wind frequently observed at low and declining bulk flow speeds.

\section{Non-Compressive Density Enhancerents in the Solar Wind}

High speed solar wind streams steepen as they progress outward frow the sun. Material is rearranged within the streans as a result of this steepening. High der.sities are found on the leading edges of streams whert waterial is compress 2d; and low densities are found in the centers and on the trailing edges of streams where rarefactions ocrur (e.g. Neugebiner and Snyder, 1966; Carov:1lano and Siscoe, 1969; Gosling et al., 1972; Ilundhauser, 1973). This rearrangement of material within streams as they nove outrard from the sun is a mijor suurce of density variability in the solar wind at 1 AU. Nevertheless, large density signals often occur at low and declining solar wind speeds which apparently do not ieflect directly this rearrargenent process (c.8. Beliher and Davis, 1971; Gosling et al., 1972; Pizzo et al., 1973).

Examples of non-compressive deusity enhancerents (1.e. density cnhancements not associated with positive speed gradients) car: be seen in Figure 6 where 3-hour averages of the solar wind speed, density, and proton temperature have been plotted for 1 solar rotation in late 1973. Intervals when non-compressive density enhancenents are present are shaded in the figure. The anomalous enhancements may be ilentified not only by the lack of an assoclated positive speed gradient but also by the fact that the proton temperature is normally 180 degrees out of phase with the density (in an adiabatic compressior. the density and proton temperature vary in phase with one another). At times these non-compressive, ensity enharcements, which generally occur at speeds below $400 \mathrm{~km} \mathrm{~s}^{-1}$, can be quite common; at least 4 examples are evident in Figure 6.

A more detailed look at a non-compressive density enhancement is provided In Figure 7. Note the out of phase nature of the density and temperature variations, the change in the temperature anisotropy across the boundarles of the enhancement, and the fact that the enhancement is moving at a lower speed than the gas on either side of 1t. A sizable mass and energy signal 1s assciaced with the enhancement. If we as... me the enhancement fills $1 / 16$ of $4 \pi$ sterradians centered on ric sun, then the integrated mass and energy olgnal for this particular event is approximately $5 \times 10^{16}$ gms and $1.4 \mathrm{x}$ $10^{32}$ ergs. These values are sometwhat higher than is typical for such events. Non-compressive density enhancements appear to be excellent candidates as the solar wind signals of coronai mass ejection events associated with 


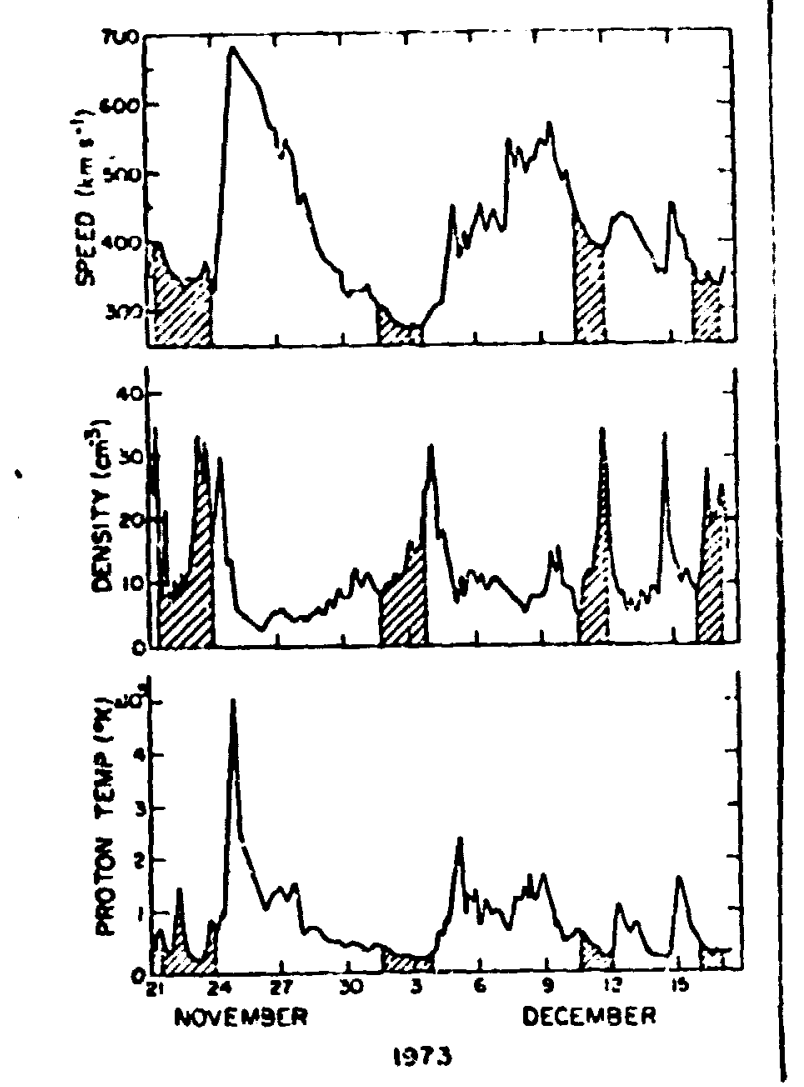

Figure 6. Three-hour averages of the solar wind speed, density, and protan tcoperature for 1 complete solar rotation in late 1973. The shaded areas emphasize large non-compressive density enhanceaents where the density and temperature are 180 degrees out of phase, and the speed is consti it or falling. Such enhancements may be caused by slow-moving coronal mass ejection events. Ifisl Imp 7, 8 data.

typical erruptive prominences. They are reasonably common, occur at low solar wind speeds, and contain sizable anounts of lass and energy.

\section{A Model Calculation of the Radial Evolution of a Coiunal Mass Ejection Event}

Consider the ejection of a dense blob of hot coronal waterlal (such as would be the case for a coronal mass ejection event) into an ambient solar wind moving at approximately the same radial speed as the blob. Because the blob is dease, it is at a higher pressure than its surroundings. This pressure imbalance causes the blob to expand more rapldiy than the surrounding gas as both travel outward from the sun. If the expansion is adiabatic, the final state obtalned far from the sun when the blob is in pressure squilibrium with its surroundings wisl be one where the blob is both denser and cooler than the surrounding gas. This is precisely the signal comon to non-compressive density enhancements in the solar wind at $1 \mathrm{AU}$.

We can make the comparison more explicit by attempting a numerical calculation of the radidl evolution of a density pulse introduced into the solar wind using the 1-dimenional, adiabatic solar wind stream code developed by Hundhausen (1973). A triangular shaped density pulse 2.5 hours wide and of amplitude 10 times the ambient density was inserted into the model code at a hellocentric distance of $0.1 \mathrm{AU}$. Figure 8 shows the subsequent evolution of the density and temperature signals associated with the pulse 5, 35, 86, and 167 hours later. As expected, at large heliocentric distances the pulse (Indicated by the cross-hatched areas) is both denser and 

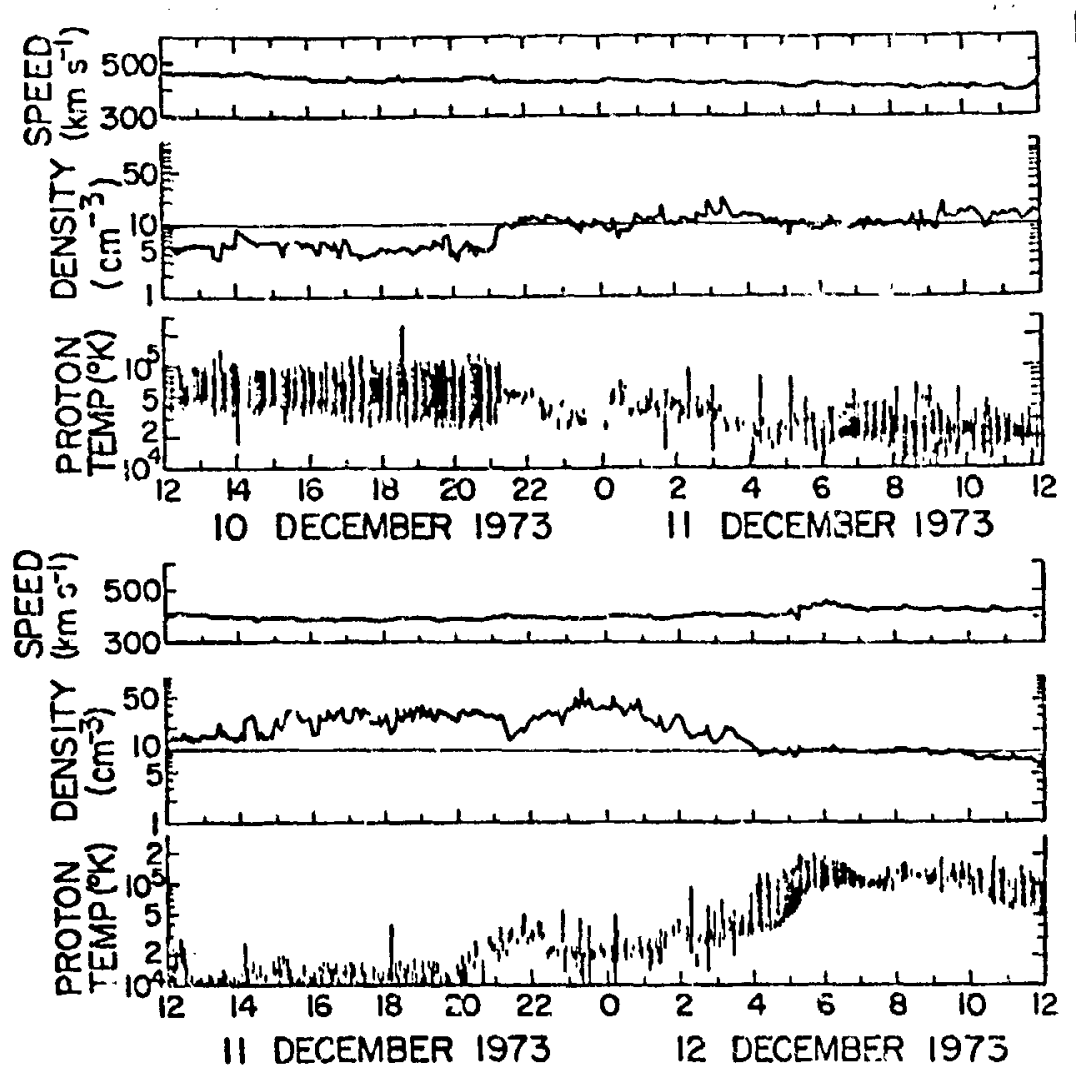

Figure 7. The non-compressive density enhancement of 10-1? December 1973 The tops and botcoms of the vartical bars in the temperature plots indicate the maximum and minimum proton temperatures associated with the velocity distribution function. The density and temperature are out of phase for nost of the event. LASL Imp 7,8 data.

cooler than its surroundings. In addition, the model calculation suggests that a density and temperature signal (i.e. a pressure signal) propagates backward and forward from the original density pulse. This additional signal has not yet be $\eta$ identified in the solar wind data; it may be an artifact of a 1-dimensionas calculation.

The purpose of the above calculation is to 11lustrate how slow moving coronal mass ejecta might evolve with increasing distance from the sun. In practice, the evolution is undoubtedly mora complex than this. We expect 2 and 3-dimensional effects to be important in damping out the pressure signal propagating outward from the density pulse, and the magnetic field should affect the evolution close to the sun as we11. Further, because these events are slow moving, many will be swept up by high speed streams which follow. Such sweeplng up effects are almost certainly the cause of abnornally large density compressions associated with some small cmplitude high speed streams.

\section{Concluding Comments}

As we have discussed, there appear to be two different classes of cororial mass ejection events - 1) the more common eruptive prominence assoclated events, and 2) the large flare assoctated events. A distinguishing tralt between tnese tro classes of events is their outward speed; on tire average the flare associated events travel more than twice as fast as the prominence associated events. The average mass and energy content of the 

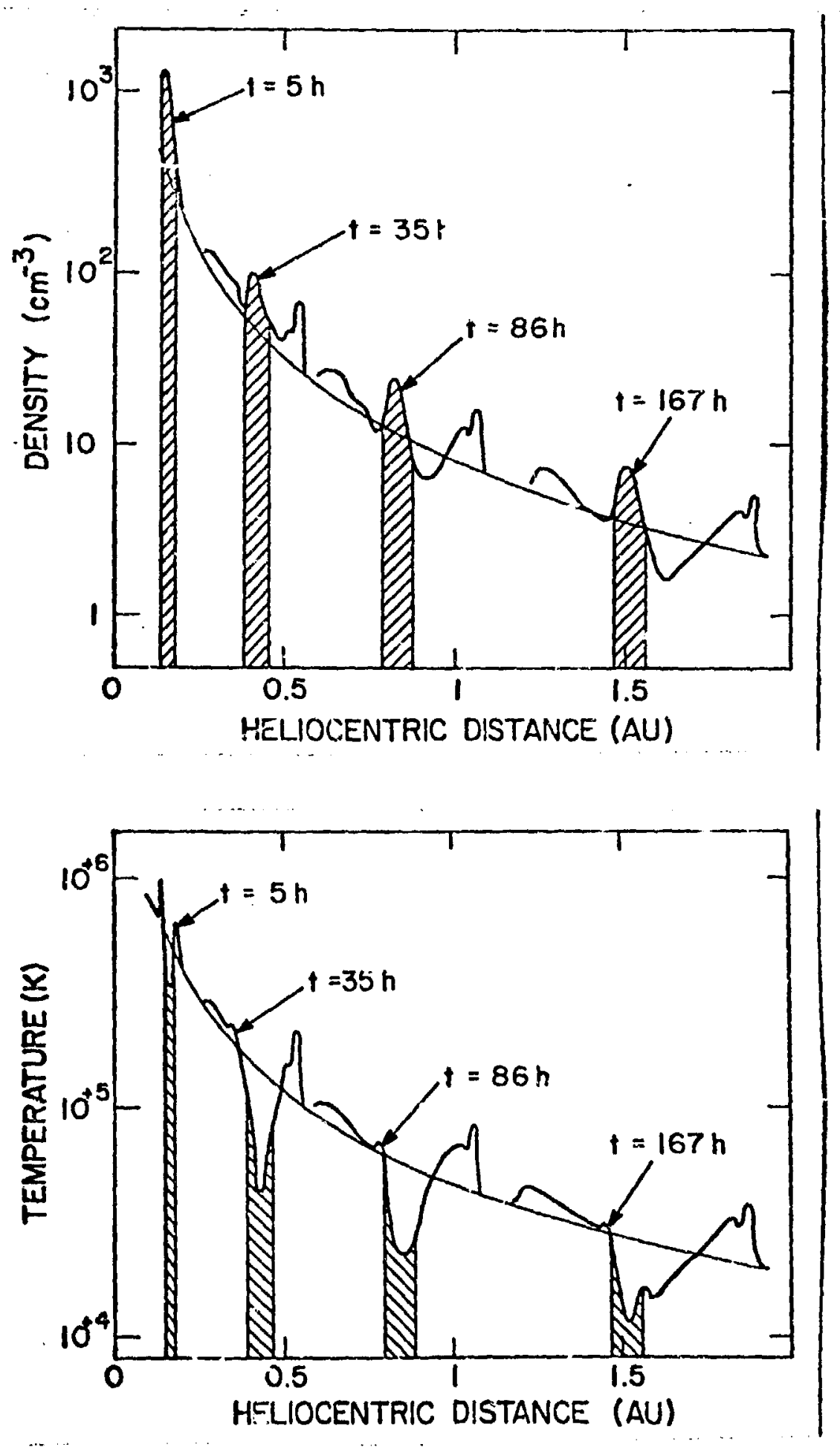

Pigure 8. The radial evolution of temperature and denstty for a short duration density pulse introduced into the solar wind $t=0$ hours. The shaded reglons indicate the materlal originally within the density pulse; this materlal cools relative to the surrounding gas as the pulse expands. 
two classes of events may be different as well, the flare assoclated events being more massive and energetic. These differences are reflected in the way the two classes of events affect the solar wind at $1 \mathrm{AU}$. The more rapidly moving flare events generally produce shock wave disturbances at $1 \mathrm{AU}$, while the s?.ower mcving prominence events generally do not. We have suggested that the latter events may be the sources of the relatively cunmon

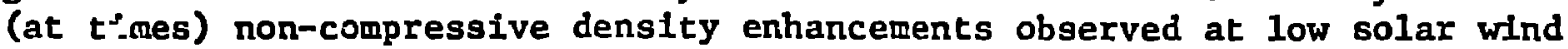
speeds away fron rising speed gradients.

Statistical studies of shock wave disturbances observed near $1 \mathrm{AU}$ strongly Indicate that most shocks at 1 AU are caused by flare associated mass ejections, and that few are caused by the steepening of $t$ igh speed solar wind streams. At larger hellocentric distances; say beyond about 3 AU From the sun, the situation is reversed. At these distances virtually every large amplitude high speed stream has steepened into a sawtooth-11ke form with one or more shocks at its leadjing edge (- dhausen and Gosling, 1976; Smith and Wolfe, 1976; Gosling et al., 1976c). These shocks are far more common than flare associated shocks. At least 8 such shocks can be seen in the two successive 25-day sequences of Ploneer 10 solar wind speed data taken between 4.03 and 4.23 AU and dispiayed in Figure 9. Because high speed streams during this interval generally originate in resivins where the sun is inactive (i.e. coronal holes) and because stream steepening is strictly an interplanetary phenomenon, most shocks in the solar wind at large heliocentric distances have little to do with solar activity.

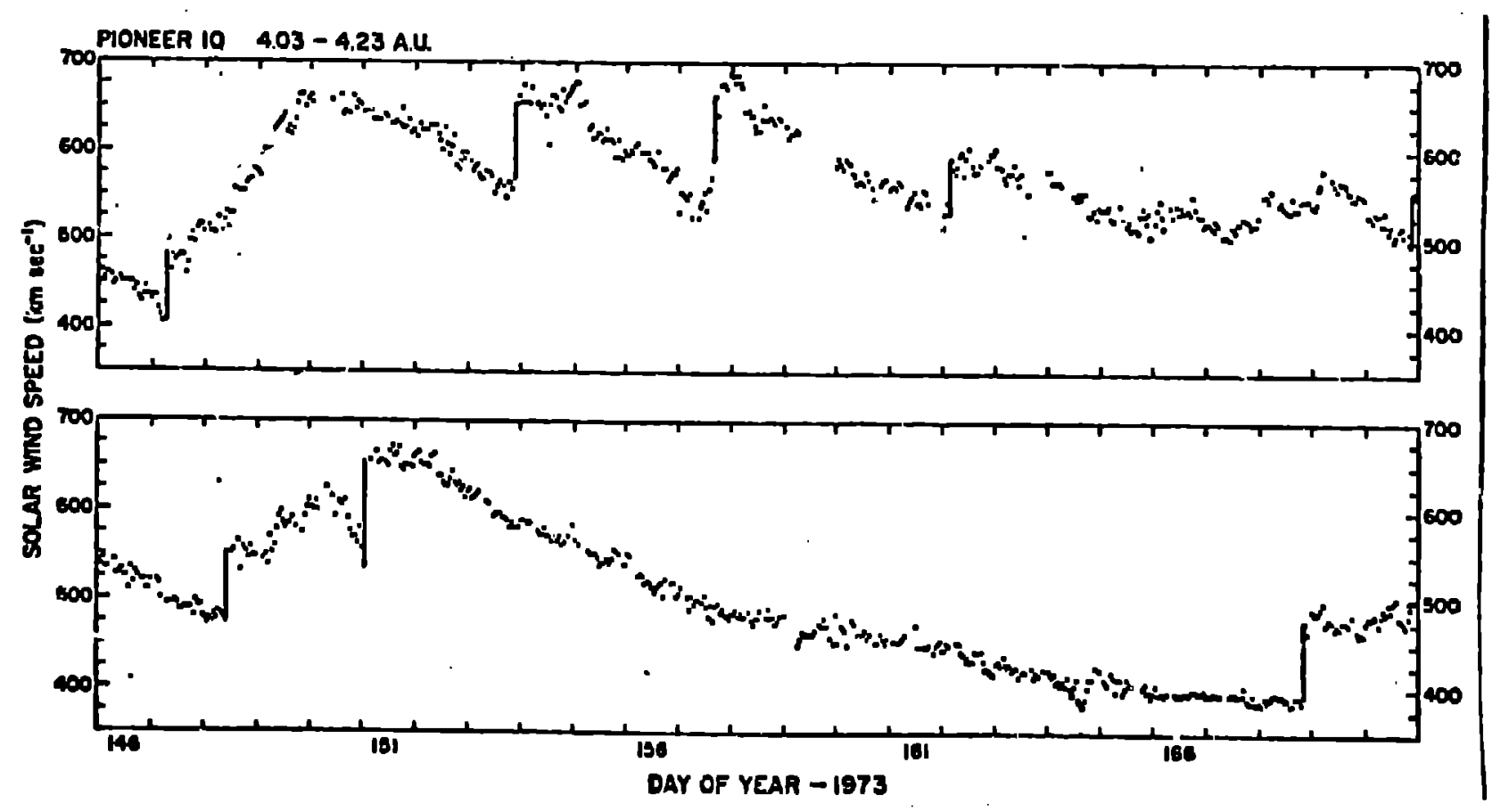

Figure 9. One hour values of the soler wind speed observed by Plonesr 10 during a 50 day perlod when the spacecrafe moved between 4.03 and 4.23 AU. The vertical lines emphasize the numerous shocks ussoclated with high opeed streams at these large distances from the sun. From Hundhausen and Gosilng (1976). 


\section{Acknowledgementg}

The author's work on coronal mass efection events was done largely witle a member of the Skylab coronagraph experfment team at the High Alt1tnde Observatory. The collaboration of his colleagues there is appreslated. In addition, spectal thanks are due to S. J. Bame, J. R. Asbrioge, and W. C. Feldman of LASL for permission to present the previously unpublished Figures 6 and 7, to A. J. Hundhausen and V. Pizzo for the computer runs which produced Figure 8, and to E. Hildner for collaborative work on non-compresef jnal density enhancements.

This work was performed under the auspices of the U.S. Energy Research and Development Adminfitration.

\section{References}

Belcher, J. W. and L. Davis, Jr. (1971): Large-amplitude Alfven waveo in the interplanetary medium, 2. J. Geophys. Res., 76:3534.

Brueckner, G. E. (1972): The coronal origin of a solar flare (abstract). Buil. Amer. Astron. Egc., 4:379.

Carovillano, R. L. ana G. L. Siscue (1965): Corotating structure in the solar wind. Solar Phys., 8:401.

Chao, J. K. and R. P. Leppling (1974): A correlative study of SSC's, Interplanetary shocks, and solar activity. I, Geophys. Res., 79:1799.

Dav1s, L. (1966): Models of the interplanetary flelds and plasm, flow. In The Solar Wind, edited by R. Mackin and M. Neugebauer, Pergamon press, pp. 147-164.

Demastus, H. L., W. J. Wagner, and R. D. Robinson (1973): Coronal disturbances, 1: Fast transient events observed in the green coronal emis- Ion Iixe during the last solar cycle. Solar Phys., 31:449.

Dulk, G. A., S. F. Smerd, R. M. Macqueen, J. T. Gosling, A. Magun, R. T. tewart, R. V. Sheridan, R. D. Robinson, and S. Jacques (1976): White 1isht and radio studies of the corunal transient of 14-15 September 197:l: Material mottons and magnetic field. Accepted by Solar Phys.

Gold, T. (1959): Plasma and magnetic field in the solar system. J. Geophzs. Res., 64:1665.

Gosling, J. T. (1975): Large-scale Inhomogenelties In the solar: wind of solar origin. Revs. Geophys, and Space Phys., 13:1053.

Gosiling, T, T., A. J. Hundhausen, V. P1zzo, and J. R. Asbridge (1972): Compressions and rarefactions in the solar wind: Vela 3 . J. Gerophys. Res., $77: 5442$.

Gosilng, J. T. and E. C. Roelof (1974): A comment on the detection of closed magnet1c structures in the selar whd. Solar Phys., 39:405. 
Gosling, J. T., E. Hildner, R. M. Macqueen, R. H, Munro, A. I. Poland, and C. L. Ross (1974): Mass ejections from the sun: $\Lambda$ view from Skylab. J. Geophys. Res., $79: 4581$.

Gosling, J. T., E. Hildner, R. M. Macqueen, R. H. Munro, A. I. Poland, and C. L. Ross (1975): Direct observations of a flare related coronal and solar wind disturbance. Solar Phys, 40:439.

Gosling, J. T., E. Hildner, R. M. Macqueen, R. H. Mur.ro, A. I. Poland, and C. L. Ross (1976a): The speeds of coronal twiss efection events. Accepted by Solar Phys.

Gosling, J, T., J. R. Asbridge, S. J. Bame, and W. C. Faldman (1976b): Soler wind speed variations: 1962-1974. Accepted by J. Geophys. Res.

Gosling, J. 'T., A. J. Hundhaugen, and S. J. Bame (1976c): Solar wind gtream evolution at large heliocentric distances: Experimental demonstration and the test of a model. Accepted by J.Geophys. Res.

Hansen, R. T., C. J. Garcla, S. F. Hansen, and E. Yasukawa (1974): Abrupt depletions of the Inner corona. Pub. Astron. Soc. Pactefc, 86:500.

H1ldner, E., J. T. Gosling, R. M. Macqueen, R. H. Munro, A. I. Poland, and C. L. Ross (1975a): The large coronal transient of 10 June 1973 I: Observational description. Solar Phys., 42:163.

HIldner, E., J. T. Gosling, R. T. Hansen, רd J. D. Bohlin (1975b): The oources of material comprising a mass ejection coronal transient. Solar Phys., 45:363.

Hildner, E., J. T. Gosling; R. M. MacQueen, R. H. Munro, A. I. Poland, and C. L. Ross (1976): Frequency of coronal transients and solar activity. Accepted by Solar Phys.

Hundhausen, A. J. (1972a): Interplanetary shock waves and the structure of solar wind disturbances. In Solar Wind, edtted by C. P. Sonett, P. J. Colleman, Jr., and J. M. W11coX, NASA SP-308, pp. 393-417.

Hundhaupen, A. J. (1972b): Coronal Expansion and Solar Wind, SpringerVerlag, New York.

Hundhausen, A. J. (1973): Nonlinear model of high-speed solar wind streams. J. Geophys. Res., $78: 1528$.

Hundhausen, A. J. and R. A. Gentry (1969): Numerical olmulation of flaregenerated distrubances in the oolar wind. J. Geophys. Reg., 74:2908.

Hundhausen, A. J. and J. T. Gooling (1976): Solar wind atructure at large hellocentric diatances: An Interpretntion of Ploncer 10 obseivaciona. J. Geophys. Rea.. $81: 1436$. 
Hundhausen, A. J., R. T. Hansen, S. F. Hansen, H. C. Feldman, J. R. Asbridge, and S. J. Bame (1976): The evolution of coronal and solar wind structure in 1973 and 1974 (abstract). International Symposium on Solar-Terrestrial Physirs, Boulder, CO, June 1976.

Koomen, M., R. Howard, R. Hansen, and S. Hansen (1974): The coronal transient of $16 \mathrm{June} 1972$. Solar Phys., 34:447.

Macqueen, R. M., J. A. Eddy, J. T. Gosling, E. Hildner, R. Il. Munro, G. A. Newkirk, Jr., A. I. Poland, and C. L. Ross (1974): The outer solar corona $=0$ observed from Skylab: Prelininary results. Astrophys. J., $187:$ L 85 .

Munro, R. H., J. T. Gosling, E. Hildner, R. M. Macqueen, A. I. Poland, and C. L. Ross (1976): Associations of coronal transients with other forms of solar activity. To be subnitted to Solar Phys.

Neugebauer, M. and C.W. Snyder (1966): Mariner 2 observations of the solar wind, 1: Average properties. J. Geophys. Res., 71:4469.

Öhman, Y. (editor) (1968): Mass Motions in Solar Flares and Related Phenomena, Almquist and Wiksel, Stockholn.

Parker, E. N, (1959): Extension of the solar corona into interplanetary space. J. Geophys. Res., $64: 1675$.

Parker, E. N. (1961): Sudden expansion of the corona following a large solar flare and the attendant magnetic fleld and cosmic ray effects. Astroptivs. J., 133:1014.

Plzzo, V., J. T. Gosling, A. J. Hundhausen, and S. J. Bame (1973): Large-scale dynamical effects upon the solar wind ilow parameters. J. Geouhys. Res., $78: 61,69$.

Poldnd, A. I. and R. H. Nunro (1976): Interpretation of broadband polarimet $x y$ of solar coronal transients: Inportance of Ha emission. Accepted by Astruphys. J.

Sheeley, N. R., Jr., J. W. Harvey, and W. C. Feldean (1976): Coronai holes, solar whid streams, and recurrent geomagtnet1c disturtances: 1973-1976. Accepted by Solar Phys.

Smard, S, F. and G. A. Dulk (1971): 80 the radlohellograph evidence of moving type IV burats and coronal mapantic flelds. In Solar Magnetlc Flelds, edited by R. Howard, D. Reldel, Dordrecht, Netherlands, Pp. 616-641.

smtth, E. J. and J. H. Wolfe (1976): Observations of Interaction reglons and corotating shocks between one and flve $A U:$ Ploneers 10 and 11 . Grophye. Res. Lette., 3:137. 
Stewart, R. T., M. K. McCabe, M. J. Koonen, R. T. llansen, and G. A. Dulk (1974a): Observations of coronal disturbances from 1 to $9 \mathrm{R}_{0} \mathrm{I}$ : First event of 1973 January 11. Solar Phys., 36:203.

Stewart, F. T., R. A. Howard, S. F. Hansen, T. Gergely, and M. Kundu (19746): Observations of coronal disturbances from $I$ to $9 R_{0}$ II: Second event of 1973 January 11. Solar Plivs., 36:219.

Stone, R. G. (1974): Traveling solar radio bursts. In Solar Wind Three, edited by C. T. Russell, UCLA, pp. 72-97.

Tandberg-Hanssen, E. (1967): Solar Activity, Blalsdell Publishing Co., Walthaw, MA.

Wild, J. P. and S. F. Smerd (1972): Radio bursts from the solar corona. Ann. Revs. Astron. and Astrophys., 10:159. 